\title{
CARACTERIZAÇÃO DA ATIVIDADE TURÍSTICA/LAZER DO PARQUE ESTADUAL MARINHO DE AREIA VERMELHA (CABEDELO/PB)
}

\author{
Rhayany Juvêncio Costa ${ }^{1}$ e George Emmanuel Cavalcanti de Miranda ${ }^{2}$
}

\begin{abstract}
Resumo: O Parque Estadual Marinho de Areia Vermelha (PEMAV) (Cabedelo - PB) apresenta-se como uma formação recifal de origem arenítica que margeia um banco de areia e se comporta como um atrativo turístico da região. O objetivo deste estudo foi caracterizar as formas de uso e ocupação do PEMAV e as áreas prioritárias de manejo visando fornecer subsídios para o gerenciamento do parque. Os processos metodológicos envolveram visitas a campo realizadas durante a maré baixa no período de dezembro de 2014 a junho de 2015 e contemplou duas etapas, a análise dos impactos ambientais e a determinação das áreas consideradas como prioritárias para o recebimento de ações de manejo. No total foram identificados 9 tipos de impactos. As áreas/atividades cujas ações de manejo são mais urgentes foram: caminhada/mergulho (snorkeling) no platô recifal; lazer (caminhada, banho de sol, lazer nas mesas/sombrinhas) no banco de areia e atracagem de catamarãs e lazer (banho) dos usuários na área de fundeio.
\end{abstract}

Palavras-chave: Ambientes recifais. Areia Vermelha. Impactos ambientais.

\section{Introdução}

A zona costeira e marinha brasileira se estendem por uma área de 4,5 milhões de $\mathrm{km}^{2}$ e apresentam-se como áreas de grande interesse econômico. Os ecossistemas que compõem as zonas costeiras estão entre os mais vulneráveis e a intensidade de usos e ocupação as quais estes ambientes estão sujeitos torna necessário o desenvolvimento de estudos que contribuam para o ordenamento sustentável (MOURA, 2012). Estima-se que cerca de dois terços da população mundial habite a zona costeira que corresponde a menos de $15 \%$ da superfície terrestre, tornando o ecossistema costeiro bastante ameaçado pelas atividades antrópicas (SOUZA, 2007).

O turismo tem se inserido nos espaços litorâneos e a tendência é que a atividade se expanda acelerando o crescimento dos fluxos turísticos nessas áreas. No ambiente marinho, o crescimento da prática turística tem como representante 0 turismo náutico, segmento do turismo ligado à prática de atividades de lazer/recreação em contato com o mar (CARRASCO, 2001).

A expansão da atividade náutica sem o adequado planejamento pode ocasionar impactos socioambientais capazes de comprometer a saúde do ambiente natural e em longo prazo, tornar a prática da atividade insustentável (MEDEIROS, 2011).
A partir de 1970 a problemática ambiental ligada ao turismo passa a ganhar destaque, a qualidade ambiental torna-se elemento importante induzindo o turismo a considerar os impactos causados ao meio ambiente natural e a discutir os graves problemas de ordem socioambiental causados as destinações receptoras do turismo massificado (PIRES, 2004).

De acordo com Ruschmann (1993, p. $57)$ entende-se como "[...] impacto ambiental todas as alterações que ocorrem nas propriedades físicas, químicas e biológicas do meio ambiente natural, causadas por qualquer forma de matéria ou energia resultante das atividades humanas $[\ldots]$ ".

Nos ambientes recifais, os principais impactos ambientais relacionados aos usos turísticos e recreativos inadequados, incluem danos como: pisoteio pelos turistas ocasionando a destruição e retirada da cobertura vegetal; lançamento de resíduos sólidos; retirada de substratos para fins artesanais/ornamentais (Ex.: confecção de souvenires); coleta de exemplares da fauna e flora para a aquariofilia; destruição das formações pela prática de mergulho (máscara e snorkel ou scuba) sem cuidados (CORREIA; SOVIERZOSKI, 2005).

$\mathrm{Na}$ costa paraibana as formações recifais são distribuídas desde o litoral norte, próximo à desembocadura do rio Mamanguape e da cidade de Baia da 


\section{REA - Revista de estudos ambientais (Online) v.18, n. 1, p.57-65, jan./jun. 2016}

Traição, na região central, próximo ao estuário do Rio Paraíba, se estendendo ao sul até os limites com Pernambuco (COSTA et al., 2007). O Parque Estadual Marinho de Areia Vermelha (PEMAV), localizado no do município de Cabedelo é dotado de uma beleza natural que atrai visitantes de todo o Brasil, representando um dos atrativos turísticos em destaque da região (LOURENÇO, 2010).

O processo de planejamento tem relação com 0 estudo da realidade, direcionado pelos objetivos da pesquisa, e com a elaboração e aplicação de um plano ligado à análise das ações mais adequadas que implicarão em interferência no ambiente (BRAGA, 2007). No estudo da realidade atividades de diagnóstico servem para conhecer as condições em que se encontram a área de estudo. "Todo processo de planejamento e/ou reestruturação de um destino turístico deve iniciar-se com um diagnóstico, pois antes de resolver um problema é necessário identificar as características que o envolvem e a importância das mesmas." (GÂNDARA et al., 2007, p.188).

A pesquisa buscou caracterizar e identificar as formas de uso e ocupação do
PEMAV e os impactos decorrentes da atividade turística/lazer, bem como as áreas prioritárias de manejo de maneira a fornecer subsídios para o processo de gerenciamento costeiro, à medida que enriquece o banco de informações/dados relacionados ao PEMAV.

\section{Metodologia}

\section{1 Área de estudo}

O PEMAV apresenta-se como uma formação recifal de origem arenítica margeado por um banco de areia. Possui 3 km de extensão (Norte-Sul) e localiza-se a cerca de $1000 \mathrm{~m}$ da praia de Camboinha no município de Cabedelo, Paraíba (07 $00^{\circ} 41$, $95 " S$ e $034^{\circ} 48^{\prime} 58,02 "$ O) (GONDIM et al., 2011) (Figura1). Tornou-se unidade de conservação por meio do decreto estadual n. $^{\circ} 21.263$ de 28 de agosto de 2000 (PARAÍBA, 2007). Durante a maré baixa quando o banco de areia e parte do platô recifal emergem, ocorre a formação de várias piscinas naturais, ocorrendo a realização da atividade turística (LOURENÇO, 2010).

Figura 1 - Mapa da localização de Areia Vermelha
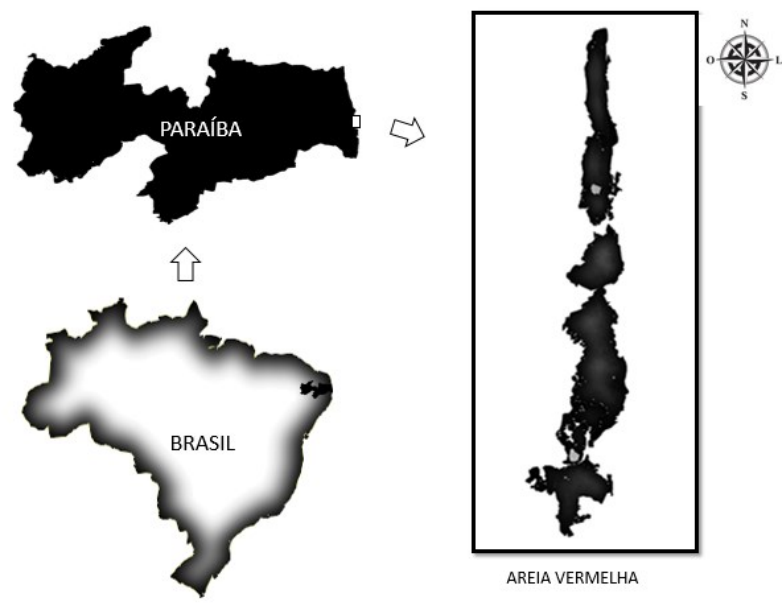

Fonte: Autores (2016)

\subsection{Métodos e técnicas}

A metodologia de caráter exploratório envolveu visitas a campo realizadas durante a maré baixa no período de dezembro de 2014 a junho de 2015 e contemplou duas etapas, a análise dos impactos ambientais e a determinação das áreas consideradas como prioritárias para o recebimento de ações de manejo.

Por meio do registro de fotografias, observação in loco e mergulhos em apneia, foi feita uma análise dos principais impactos humanos nas regiões do mesolitoral (banco de areia e platô recifal) e nas regiões do infralitoral raso (região permanentemente submersa). 


\section{REA - Revista de estudos ambientais (Online) v.18, n. 1, p.57-65, jan./jun. 2016}

A intensidade dos impactos foi estudada através dos procedimentos de avaliação adotados por Costa et al. (2007), a partir dos quais foram definidos o Valor Arbitrário dos Impactos (VAI) e o Peso de cada Impacto $(\mathrm{PI})$. Da relação entre os dois (VAI x PI) obteve-se uma escala quantitativa para cada atividade. Para uma análise comparativa foram adotados os seguintes critérios de pontuação: 0 (ausente); 1 (impacto de pequena expressividade); 2 (impacto moderado) e 3 (impacto extremo). Quanto ao nível de importância e intensidade de cada um dos impactos identificados foi utilizado os seguintes pesos: 1 (pequena importância/intensidade),

(importância/intensidade moderada) e 3 (alta importância/intensidade elevada).

Para a identificação de locais prioritários de uso e visitação, bem como a priorização de áreas para o manejo foi utilizada a metodologia de Manejo de Impactos de Visitação (MIV) (Brasil, 2011b), focando na experiência do visitante e na conservação dos recursos naturais. Para o processo de identificação das atividades por lugares prioritários foi feita uma listagem das áreas e atividades de visitação existentes na unidade de conservação através de análise documental e observação in loco. Em seguida baseado na MIV os seguintes critérios de pontuação foram aplicados para identificação das áreas/atividades mais relevantes: a) Intensidade da demanda (Grande demanda - 3; Demanda em níveis razoáveis - 2 e Pouca demanda - 1), b) Impactos evidentes (Impactos visíveis - 3, Impactos pouco evidentes - 2 e Impactos não perceptíveis - 1) e c) Zona em que a atividade ocorre, com base nas zonas definidas por Lourenço (2010): zona de uso intensivo (1) zona de uso extensivo (2) e zona primitiva (3).

\section{Resultados}

\subsection{Identificação dos impactos ambientais}

No total foram identificados 9 tipos de impactos (Tabela 1). Entre estes, pode-se reconhecer como aqueles mais expressivos os seguintes: poluição por resíduos sólidos (Figura 2); alteração da paisagem cênica pelo elevado número de embarcações (Figura 3); alteração da paisagem cênica pelo elevado número de mesas/sombrinhas (Figura 3) e pisoteio (Figura 4). Dentre os impactos menos expressivos identificou-se: poluição pelos combustíveis das embarcações; revolvimento do sedimento por banho/mergulho dos usuários; retirada de substratos das formações recifais como souvenir (Figura 4); pressão ambiental pelo tipo de alimentação comercializada.

Tabela 1 - Os principais impactos ambientais oriundos da atividade turística/lazer em Areia Vermelha. (VAl= Valor Arbitrário dos Impactos; PI = VAl x Pesos atribuídos a cada impacto)

\begin{tabular}{|c|c|c|c|}
\hline IMPACTOS AMBIENTAIS & VAI & Peso & $\begin{array}{c}\text { PI } \\
\text { (Vai x Peso) } \\
\end{array}$ \\
\hline Poluição por resíduos sólidos & 3 & 3 & 9 \\
\hline $\begin{array}{l}\text { Alteração da paisagem cênica pelo } \\
\text { elevado número de embarcações }\end{array}$ & 3 & 3 & 9 \\
\hline $\begin{array}{l}\text { Alteração da paisagem cênica pelo } \\
\text { elevado número de mesas/sombrinhas }\end{array}$ & 3 & 3 & 9 \\
\hline Pisoteio sobre o ambiente recifal & 2 & 3 & 6 \\
\hline $\begin{array}{l}\text { Poluição pelos combustíveis das } \\
\text { embarcações }\end{array}$ & 2 & 2 & 4 \\
\hline $\begin{array}{l}\text { Revolvimento do sedimento por } \\
\text { banho/mergulho dos usuários }\end{array}$ & 2 & 2 & 4 \\
\hline $\begin{array}{l}\text { Retirada de substratos das formações } \\
\text { recifais como souvenir }\end{array}$ & 1 & 2 & 2 \\
\hline $\begin{array}{l}\text { Pressão ambiental pelo tipo de } \\
\text { alimentação comercializada }\end{array}$ & 1 & 1 & 1 \\
\hline
\end{tabular}




\section{REA - Revista de estudos ambientais (Online) v.18, n. 1, p.57-65, jan./jun. 2016}

Figura 2 - Poluição por resíduos sólidos: (A) Parte de garrafa de vidro; (B) Fragmento de plástico; (C) Copo descartável; (D) Colher descartável; (E) Fragmentos de caranguejo; (F) Fragmento de madeira
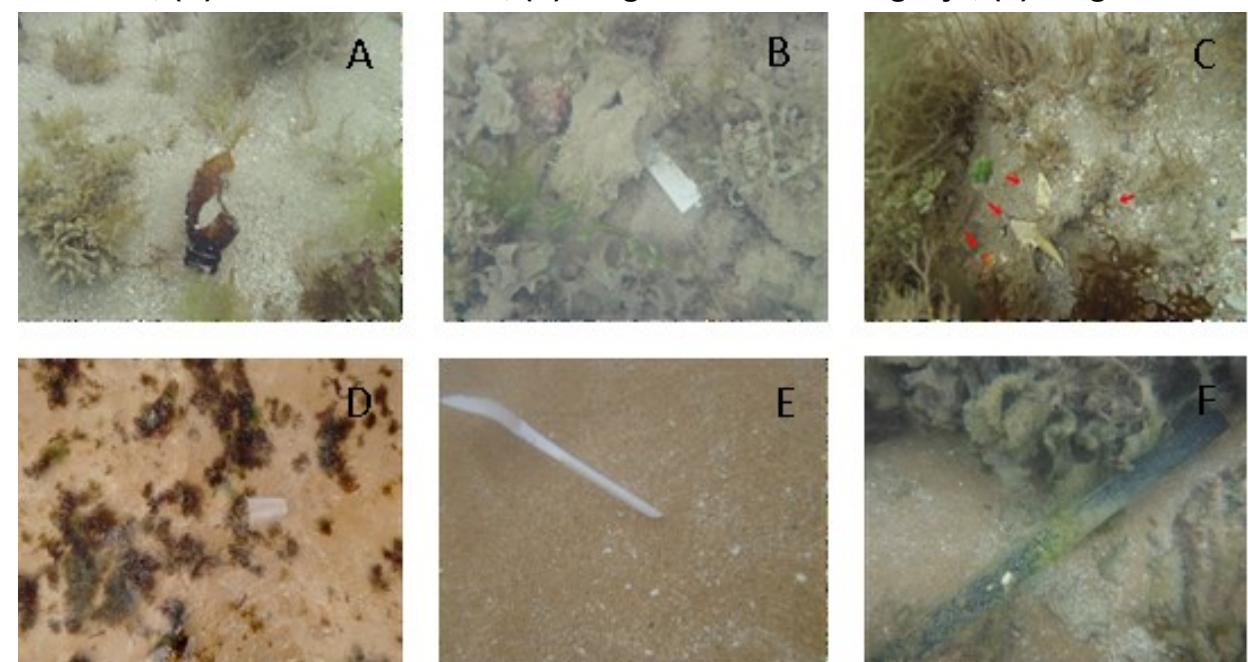

Fonte: Autores (2016)

Figura 3 - Alteração da paisagem cênica pelo elevado número de embarcações elevado número de mesas/sombrinhas relativa à atividade turística em Areia Vermelha

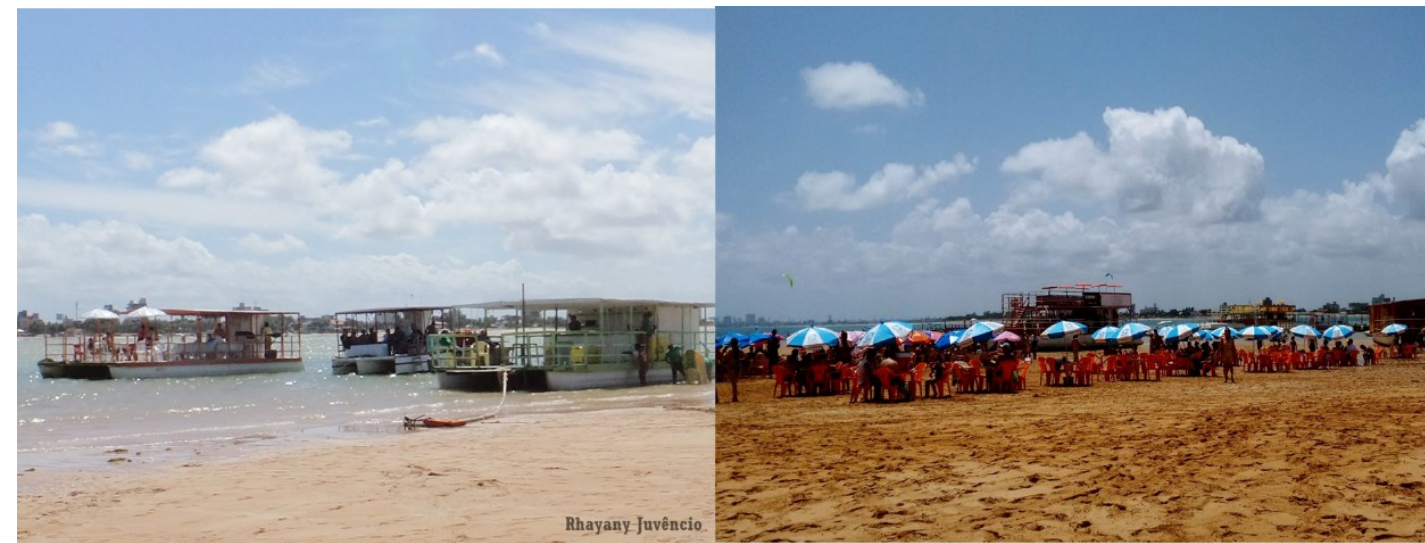

Fonte: Autores (2016)

Figura 4 - Impactos ambientais (A) Usuários caminhando/mergulhando na área do platô recifal em Areia Vermelha - Área de circulação proibida. (B) Detalhe de substratos das formações recifais retirados por usuários

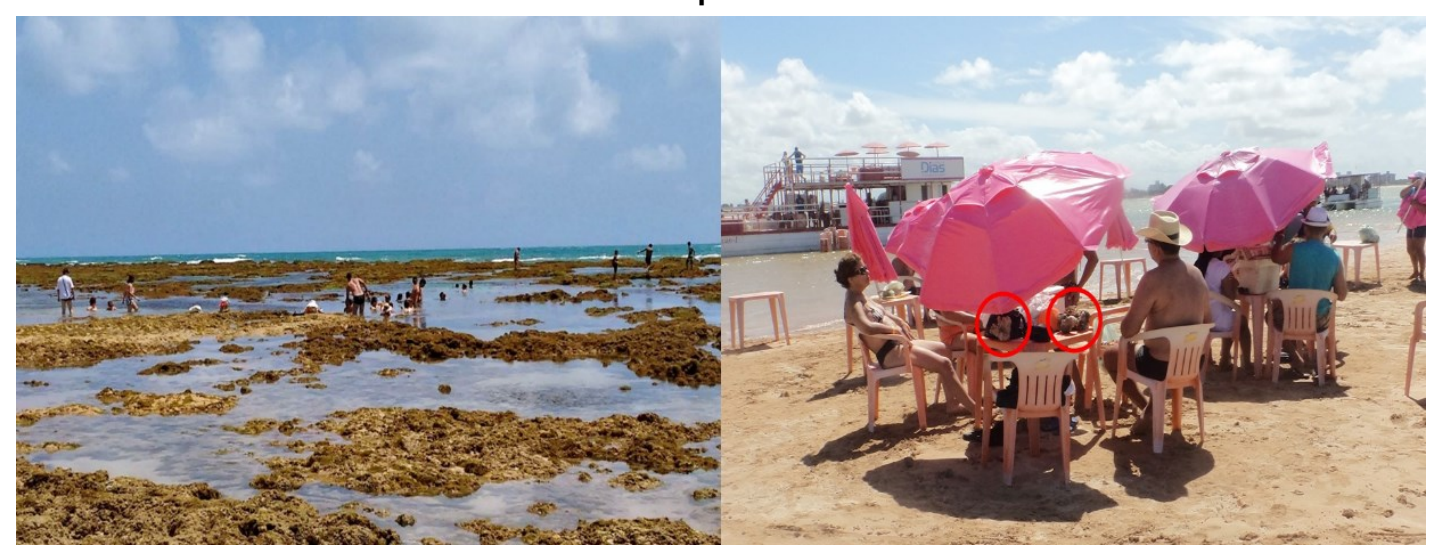

Fonte: Autores (2016)

De acordo com os resultados, se continuados, os impactos identificados no
PEMAV podem comprometer não só a saúde do ambiente natural, bem como a realização 


\section{REA - Revista de estudos ambientais (Online) v.18, n. 1, p.57-65, jan./jun. 2016}

do turismo a longo prazo. O pisoteio sobre os recifes durante caminhadas no platô recifal ou mesmo associado à intensificação da prática de mergulho com snorkel pode promover a quebra do substrato e danos aos organismos bênticos comprometendo a conservação da biodiversidade local. Outra consequência associada ao pisoteio se refere ao aumento da quantidade de material em suspensão na água, pois ao pisar no chão os usuários agitam o sedimento, o que implica na qualidade da água e no nível de incidência de luz sobre os organismos. De acordo com Brasil (2011a) a quantidade excessiva de sedimento em suspensão na água prejudica $\mathrm{o}$ crescimento $\mathrm{e}$ a alimentação dos corais tornando alguns mais suscetíveis a desenvolver doenças. Apesar de a prática do snorkeling/mergulho ou caminhadas sobre os recifes não serem permitidas na área do platô recifal no PEMAV usuários foram comumente encontrados andando e/ou praticando snorkeling nestas áreas. Para Segal et al. (2007) o pisoteio durante as caminhadas, realizadas de forma desordenada, pode ocasionar morte de partes inteiras da formação recifal, tornando de suma importância orientações do condutor para minimizar os danos sobre o ambiente recifal e garantir a segurança do visitante.

Detritos marinhos são definidos como "[...] todos os materiais residuais sólidos, fabricados ou processados que entram no ambiente marinho a partir de qualquer fonte." (COE; ROGERS, 1997, p.31). A poluição por resíduos sólidos no PEMAV é produto da comercialização de alimentos e bebidas pelos barcos restaurantes, o impacto é evidenciado pela presença de colheres, pratos, copos, canudos e palitos de churrasco encontrados com facilidade, principalmente na região do banco de areia próxima às mesas/sombrinhas. Na região do infralitoral, pouco resíduo sólido é encontrado quando comparado à região do banco de areia, porém nesta, fragmentos de caranguejo e alimento comercializado localmente, são facilmente encontrados durante mergulhos. Detritos lançados no mar podem circular por semanas ou até anos na água ou ainda, serem imediatamente levados à terra firme, esta mobilidade garante a capacidade de gerar impactos que podem ser observados em nível local, regional ou global (COE; ROGERS, 1997).

O aumento da procura por lugares que forneçam sensação de bem-estar valoriza o papel da paisagem na atratividade de uma destinação turística. Ao se deparar com a imagem de uma paisagem agradável, com elevado poder de beleza cênica, prazer e bem estar o indivíduo tende a se projetar neste local (PACHECO; OLIVEIRA, 2011). O elevado número de usuários, embarcações e mesas/sombrinhas ocasiona alteração da paisagem cênica no PEMAV. De acordo com Lourenço (2010) a capacidade de carga definida para Areia Vermelha é de 1225 visitas/diárias. Este valor, ainda que elevado, não foi adotado pela gestão e não existe controle sobre o número máximo de usuários na área. Quando se considera o número de usuários vindos de catamarãs, embarcações particulares (Jet ski, lancha, barco etc.) e lanchas táxi, o número é facilmente ultrapassado ocasionando uma alteração da beleza cênica local.

Assis (2011) que avaliou os principais impactos atrelados a atividade turística nas piscinas naturais de Maragogi (Alagoas) apontou que as principais alterações na área estavam ligadas à ancoragem inadequada, ao pisoteio sobre as formações recifais, a retirada de organismos para fins ornamentais, ao aumento da turbidez da água e a pesca irregular. Os danos na área tornaram-me mais intensos com o aumento da exploração do setor privado por meio de passeios, atividades de mergulho autônomos, comercialização de fotos subaquáticas e vendas de comidas e bebidas. Ainda segundo o autor, os impactos ambientais sobre a área foram minimizados mediante a aplicação de ações emergenciais que incluíram, entre outros aspectos, regulamentação da atividade turística com punição prevista em lei.

Costa e Miranda (2016) observaram que na região do PEMAV não há um processo de monitoramento contínuo, bem como não foram adotadas ações de manejo visando a sustentabilidade das atividades turísticas. Desta maneira a ausência de programas de monitoramento e manejo interferem diretamente nos resultados esperados nos processos preservação e planejamento turístico.

\subsection{Identificação das áreas prioritárias de manejo}

Após a identificação/caracterização dos principais impactos ocorrentes em Areia Vermelha foi feita uma relação das áreas por atividades de visitação existentes na unidade 


\section{REA - Revista de estudos ambientais (Online) v.18, n. 1, p.57-65, jan./jun. 2016}

de conservação detalhada no Quadro 1. Empregando-se valores baseados na intensidade da demanda, nos impactos evidentes e nas zonas de localização identificaram-se as áreas/atividades prioritárias no recebimento de ações de manejo detalhadas na Figura 5 e na Tabela 2.

Quadro 1 - Listagem das Áreas/Atividades/Impactos ocorrentes no PEMAV.

\begin{tabular}{|c|c|c|}
\hline $\begin{array}{c}\text { ATIVIDADES POR LUGAR DE } \\
\text { VISITAÇÃO }\end{array}$ & ZONAS & IMPACTOS \\
\hline $\begin{array}{l}\text { Lazer (caminhada, banho de sol, } \\
\text { lazer nas mesas/sombrinhas) no } \\
\text { banco de areia }\end{array}$ & Zona de banhistas & $\begin{array}{l}\text { 1. Poluição por resíduos sólidos } \\
\text { 2. Pressão ambiental pelo tipo de } \\
\text { alimentação comercializada } \\
\text { 3. Alteração da paisagem cênica pelo } \\
\text { elevado número de mesas/sombrinhas }\end{array}$ \\
\hline $\begin{array}{l}\text { Caminhada/Mergulho (snorkeling) } \\
\text { no platô recifal }\end{array}$ & $\begin{array}{c}\text { Zona de preservação da } \\
\text { vida marinha }\end{array}$ & $\begin{array}{l}\text { 1. Pisoteio } \\
\text { 2. Revolvimento do sedimento por } \\
\text { banho/mergulho dos usuários }\end{array}$ \\
\hline $\begin{array}{l}\text { Atracagem de catamarãs e lazer } \\
\text { (banho) dos usuários na área de } \\
\text { fundeio }\end{array}$ & $\begin{array}{l}\text { Zona para fundeio de } \\
\text { embarcações }\end{array}$ & $\begin{array}{l}\text { 1. Pisoteio } \\
\text { 2. Pressão ambiental pelo tipo de } \\
\text { alimentação comercializada } \\
\text { 3. Alteração da paisagem cênica pelo } \\
\text { elevado número de embarcações } \\
\text { 4. Poluição pelos combustíveis das } \\
\text { embarcações } \\
\text { 5. Revolvimento do sedimento por } \\
\text { banho/mergulho dos usuários }\end{array}$ \\
\hline $\begin{array}{l}\text { Atracagem de embarcações } \\
\text { particulares e lazer (banho) dos } \\
\text { usuários na área de fundeio }\end{array}$ & $\begin{array}{l}\text { Zona de fundeio de } \\
\text { embarcações }\end{array}$ & $\begin{array}{l}\text { 1. Pisoteio } \\
\text { 2. Pressão ambiental pelo tipo de } \\
\text { alimentação comercializada } \\
\text { 3. Alteração da paisagem cênica pelo } \\
\text { elevado número de embarcações } \\
\text { 4. Poluição pelos combustíveis das } \\
\text { embarcações } \\
\text { 5. Revolvimento do sedimento por } \\
\text { banho/mergulho dos usuários }\end{array}$ \\
\hline $\begin{array}{l}\text { Lazer (banho/snorkeling) dos } \\
\text { usuários na área de snorkeling }\end{array}$ & $\begin{array}{l}\text { Zona de uso turístico } \\
\text { recreativo }\end{array}$ & $\begin{array}{l}\text { 1. Pisoteio } \\
\text { 2. Revolvimento do sedimento por } \\
\text { banho/mergulho dos usuários }\end{array}$ \\
\hline
\end{tabular}

Fonte: Autores (2016)

Figura 5 - Mapa das áreas por atividades de visitação em Areia Vermelha.
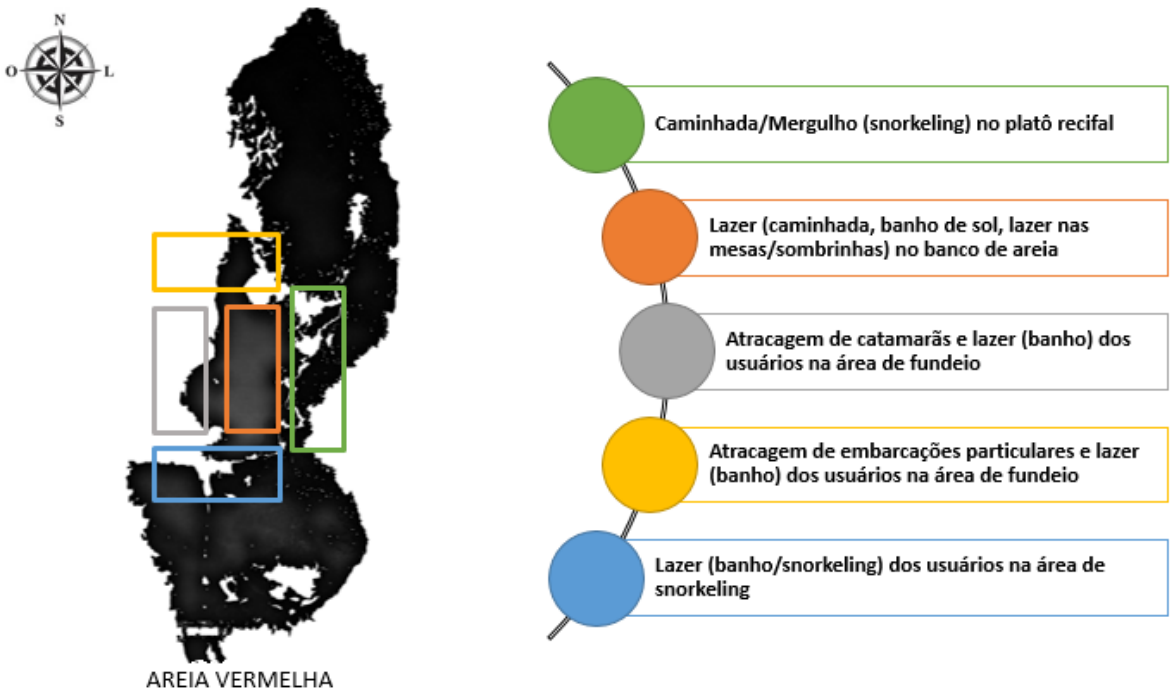

Fonte: Autores (2016) 


\section{REA - Revista de estudos ambientais (Online) v.18, n. 1, p.57-65, jan./jun. 2016}

As áreas/atividades onde as ações de manejo são mais urgentes em Areia Vermelha foram elencadas na Tabela 2.

Na Figura 5 tem-se a representação de como está estruturada as formas de uso e ocupação do PEMAV, entretanto vale salientar que a atividade turística é dinâmica, podendo ocasionar uma reestruturação das formas de ocupação e uso ao longo do tempo, o que torna necessário a realização de estudos de atualização contínuos que forneçam informações referentes as condições atuais da UC.

Tabela 2 - Áreas/Atividades prioritárias para recebimento de ações de manejo no PEMAV.

\begin{tabular}{|c|c|c|c|c|}
\hline Atividades por lugar de visitação & $\begin{array}{l}\text { Demanda de } \\
\text { visitantes }\end{array}$ & $\begin{array}{l}\text { Impactos } \\
\text { evidentes }\end{array}$ & $\begin{array}{l}\text { Zona em que } \\
\text { se localiza *2 }\end{array}$ & Total \\
\hline $\begin{array}{l}\text { Caminhada/Mergulho (snorkeling) } \\
\text { no platô recifal }\end{array}$ & 1 & 3 & 3 & 10 \\
\hline $\begin{array}{l}\text { Lazer (caminhada, banho de sol, } \\
\text { lazer nas mesas/sombrinhas) no } \\
\text { banco de areia }\end{array}$ & 3 & 3 & 1 & 8 \\
\hline $\begin{array}{l}\text { Atracagem de catamarãs e lazer } \\
\text { (banho) dos usuários na área de } \\
\text { fundeio }\end{array}$ & 2 & 3 & 1 & 7 \\
\hline $\begin{array}{l}\text { Atracagem de embarcações } \\
\text { particulares e lazer (banho) dos } \\
\text { usuários na área de fundeio }\end{array}$ & 2 & 3 & 1 & 7 \\
\hline $\begin{array}{l}\text { Lazer (banho/snorkeling) dos } \\
\text { usuários na área de snorkeling }\end{array}$ & 1 & 1 & 2 & 6 \\
\hline
\end{tabular}

- Demanda de visitantes (Grande demanda - 3, Demanda em níveis razoáveis - 2 e Pouca demanda - 1),

- Impactos evidentes (Impactos visíveis - 3, Impactos pouco evidentes - 2 e Impactos não perceptíveis - 1)

- Zona em que se localiza (Zona primitiva - 3, Zona de uso extensivo - 2 e Zona de uso intensivo - 1).

* A pontuação dos impactos evidentes será multiplicada por 2 (dois) Fonte: Autores (2016)

"[...] toda e qualquer atividade humana num ambiente natural causa algum grau de impacto." (SEGAL et al., 2007, p.5). Qualquer interferência antrópica sobre o meio ambiente irá ocasionar impacto, o que diferencia, é o nível de pressão, fraca ou intensa ao qual o ambiente está submetido. Em um estudo envolvendo formas de uso e impactos ambientais sobre os ambientais recifais Costa et al. (2007, p. 41) “[...] evidenciou que existem diferentes formas de usos dos recifes costeiros da Paraíba os quais funcionam como agentes diretos, amplificadores ou potencializadores de diferentes tipos de impactos.". A presente pesquisa apontou que existem diferentes atividades por áreas de visitação sendo desenvolvidas na extensão do PEMAV atuando como geradoras de diferentes efeitos sobre o ambiente natural (Figura 5; Quadro 1).

As áreas/atividades prioritárias de manejo identificadas representam um reflexo das diferentes formas de uso e ocupação presentes no PEMAV (Tabela 2), a caminhada/mergulho (snorkeling) no platô recifal, o azer (caminhada, banho de sol, lazer nas mesas/sombrinhas) no banco de areia e a atracagem de catamarãs e lazer (banho) dos usuários na área de fundeio, se apresentam como atividades que atuam como geradoras de pressão ambiental através do pisoteio, da poluição por resíduos sólidos, da alteração da paisagem cênica e do revolvimento do sedimento, comprometendo a qualidade ambiental e reforçando a necessidade de manejo.

A identificação das áreas/atividades prioritárias de manejo pode atuar como subsídio para o desenvolvimento de um turismo sustentável, visto que representam as zonas cujas pressões ambientais, demanda de visitas e vulnerabilidade da biodiversidade são mais evidentes.

Recentemente um Termo de Ajustamento de Conduta (TAC) (2015) implantou restrições relacionadas a comercialização e ocupação dos espaços. Ao entrarem em vigor, as novas regras, interferiram nas formas de uso e ocupação do parque e nas áreas com maior necessidade de manejo identificadas no presente estudo. As atividades de turismo/lazer no banco de areia foram as mais afetadas pelas novas regulamentações, entretanto há uma tendência de intensificação dos impactos na zona de 


\title{
REA - Revista de estudos ambientais (Online) v.18, n. 1, p.57-65, jan./jun. 2016
}

snorkeling, pois os usuários se deslocaram para esta área, não mais se concentrando no banco de areia, e sim na zona do platô recifal e de snorkeling, demonstrando claramente que o legislador teve, no caso, uma visão limitada dos impactos no PEMAV, sendo o uso de estratégias sistêmicas mais adequadas e menos susceptíveis a pressões sociais ou midiáticas.

Medidas de controle de visitação envolvendo definição de capacidade de carga, estabelecimento de zoneamento e aplicação de atividades de educação ambiental tem sido propostas para os ambientes recifais costeiros da Paraíba com atividade turística (MELO et al., 2006; MELO et al., 2008; DEBEUS, 2008; DEBEUS et al., 2012). Lourenço (2010) desenvolveu uma proposta de zoneamento e capacidade de carga para o PEMAV, no entanto como apresentado na presente pesquisa o parque ainda apresenta carências em ações de planejamento turístico tornando necessário o desenvolvimento de mais estudos capazes de preencher as lacunas de informações/dados que contribuam para um gerenciamento eficaz.

\section{Conclusões}

Conclui-se que existem diferentes atividades por áreas de visitação sendo desenvolvidas no PEMAV desencadeando diferentes efeitos sobre 0 ambiente natural. Considerando os impactos abordados, oriundos das diferentes formas de uso de ocupação do PEMAV, e as áreas/atividades prioritárias de manejo identificadas, a implementação de ações direcionadas a conservação do parque se tornam essenciais para que os danos causados aos locais de visitação sejam mínimos e permitam a conservação dos recursos naturais existentes e a realização do turismo a longo prazo.

Desta maneira, o emprego de medidas como controle do número de visitantes, controle e zoneamento da ancoragem de embarcações, restrições de acesso a zona do platô recifal, disciplinamento da comercialização, adequação do mergulho de apneia, além de sinalização e educação ambiental, se apresentam como alternativas de manejo.

\section{Characterization of Tourism Activity of the Areia Vermelha Marine State Park (Cabedelo - PB)}

\begin{abstract}
The Marine State Park Areia Vermelha - PEMAV (Cabedelo - PB) is formed by sandstone reefs surrounding a sandbar and behaves as a tourist attraction of the region. The purpose of this study is to characterize the forms of use and occupation of the PEMAV and the priority areas of management in order to provide subsidies for the management of the park. The methodology involved visits to field during low tide in the period from December 2014 to June 2015 and contemplated two stages, the analysis of the environmental impacts and the determination of the areas considered as priority for the receipt of management actions. In total were identified nine types of impacts. The areas/activities whose management actions are most urgent were: walking/diving (snorkeling) in the reefs; recreation (hiking, sunbathing, recreation on the tables/umbrellas) on the sandbar and anchoring of the boats and recreation (bath) of users in the anchorage area.
\end{abstract}

Keywords: Reef environments; Areia Vermelha; Environmental impacts;

\section{Referências}

ASSIS, C.C. Controle da visitação pública nas piscinas naturais da Costa dos Corais em Maragogi (AL). Anais do VIII Congresso Nacional de Ecoturismo e do IV Encontro Interdisciplinar de Ecoturismo em Unidades de Conservação. Revista Brasileira de Ecoturismo, São Paulo, v.4, n.4, 2011.

BRAGA, Debora. Planejamento turístico: teoria e prática. Elsevier Brasil, 2007.
BRASIL. Conduta consciente em ambientes recifais. Manual para multiplicadores da campanha. Ministério do Meio Ambiente. Secretaria de Biodiversidade e Florestas. Gerência de Biodiversidade Aquática e Recursos Pesqueiros. Brasília. 2011a. Disponível em: <http://www.mma.gov.br/estruturas/205/_arquivos/ livromultiplicador_2011_205.pdf>. Acesso em: 09 jun. 2015.

BRASIL. Ministério do Meio Ambiente. Instituto Chico Mendes. Roteiro Metodológico para manejo de impacto de visitação com Enfoque 


\section{REA - Revista de estudos ambientais (Online) v.18, n. 1, p.57-65, jan./jun. 2016}

na Experiência do Visitante e na Proteção dos Recursos Naturais e Culturais. 2011b.

CARRASCO, S. F. La relevancia del turismo náutico en la oferta turística. Cuadernos de turismo, n. 7, p. 67-80, 2001.

COE, J. M.; ROGERS, D. (Ed.). Marine debris: sources, impacts, and solutions. Springer Science \& Business Media, 1997.

CORREIA, M. D.; SOVIERZOSKI, H. H. Ecossistemas Marinhos: recifes, praias e manguezais. EDUFAL, 2005.

COSTA, R. J; MIRANDA, G. E. C de. Análise dos estudos de capacidade de carga turística para os recifes de Picãozinho, Seixas (João Pessoa-PB) e Areia Vermelha (Cabedelo-PB). Caderno Virtual de Turismo. Rio de Janeiro, v. 16, n. 1, p. 60-73, 2016

COSTA, C. F., SASSI, R., COSTA, M. A. J., \& DE BRITO, A. C. L. Recifes costeiros da Paraíba, Brasil: usos, impactos e necessidades de manejo no contexto da sustentabilidade. Revista Gaia Scientia, v. 1, n. 1, p. 37-45, 2007

DEBEUS, G. Turismo Sustentável Como Alternativa de Desenvolvimento e Conservação do Meio Ambiente em Picãozinho - Município de João Pessoa - PB. Dissertação (Mestrado em Desenvolvimento e Meio Ambiente - PRODEMA) Universidade Federal da Paraíba, João Pessoa, 2008. Disponível em:< http://www.prpg.ufpb.br/prodema/novosite/smartgc /uploads/arquivos/guilherme_debeus.pdf > . Acesso em: 10 jun. 2015.

DEBEUS, G.; LIMA, E. R. V.; CRISPIM, M. C. Proposta de Zoneamento para o Ambiente Recifal de Picãozinho, João Pessoa-PB. Revista Gaia Scientia, v.6, n.1, p.19-30, 2012.

GÂNDARA, J. M. G.; CHIQUIM, C. E.; PALUMBO, $\mathrm{G}$. \& LAGO, H. Planejamento estratégico participativo para construir o destino turístico de Foz do Iguaçu-PR. EI Periplo Sustentable, v.12, p. 185-235. 2007.

GONDIM, A. I. DIAS, T. L. P; CAMPOS, F. F; ALONSO, C; CHRISTOFFERSEN, M. L. Macrofauna bêntica do Parque Estadual Marinho de Areia Vermelha, Cabedelo, Paraíba, Brasil. Biota Neotropica, v. 11, n. 2, p. 75-86, 2011.

LOURENÇO, Liliane de Jesus Silva. Proposta de Zonemamento e Capacidade de Carga para o Parque Estadual Marinho de Areia Vermelha.
Dissertação de Mestrado (Mestrado em Desenvolvimento e Meio Ambiente - PRODEMA). UFPB. João Pessoa. 2010. Disponível em: $<$ http://tede.biblioteca.ufpb.br/handle/tede/4517\#pr eview-link0>. Acesso em: 15 ago. 2015

MEDEIROS, Márcio Bastos. Turismo Náutico em Angra dos Reis - RJ: a sustentabilidade em questão. 2011. 105 f. Dissertação (Mestrado em Desenvolvimento Sustentável). Universidade de Brasília, 2011.

MELO, R. S., CRISPIM, M. C., VIANA, E. R., \& LINS, R. P. Planejamento turístico e zoneamento ambiental: um estudo de caso nos ambientes recifais das praias do Seixas, Penha e Arraial (Paraíba, Brasil). Caderno Virtual de Turismo, v. 8, n. 2, p.23-33, 2008.

MELO, R. S.; CRISPIM, M. C.; LIMA, E. R. V.; NISHIDA, A. K. Estimativa da capacidade de carga recreativa dos ambientes recifais da Praia do Seixas (Paraíba-Brasil). Turismo-Visão e Ação, v. 8, n. 3, p. 411-422, 2006.

MOURA, M. R. Dinâmica sócioambiental da zona costeira de caucaia e aquiraz, ceará: avaliação de indicadores erosivos como subsidio para gerenciamento costeiro do estado. MercatorRevista de Geografia da UFC, v. 11, n. 25, p. 203, 2012.

PACHECO, L.D.N.; OLIVEIRA, J. P. A percepção da paisagem no turismo do campo de golfe Comandatuba Ocean Course na ilha de Comandatuba, BA. Caderno Virtual de Turismo, Rio de Janeiro, v. 11, n. 3, p.341-354, dez. 2011.

PARAÍBA. SUDEMA - SUPERINTENDÊNCIA DE ADMINISTRAÇÃO DO MEIO AMBIENTE. PORTARIA / SUDEMA/DS N. ${ }^{\circ} 002$ /2007.

PIRES, E. C. R. 70-As Inter-relações turismo, meio ambiente e cultura. 2004.

RUSCHMANN, D V. M. Impactos ambientais do turismo ecológico no Brasil. Revista Turismo em Análise, v. 4, n. 1, p. 56-68, 1993.

SEGAL, B.; CASTRO, C. B.; NEGRÃO F.; GOUVEIA, M. T. J. \& MELO, T. H. M. Turismo Sustentável em Ambientes Recifais. Projeto Coral Vivo. 2007.

SOUZA, P. F. R. de. Circulação hidrodinâmica na região costeira dos municípios de Recife e Jaboatão dos Guararapes durante o verão austral. Dissertação (Mestrado em Oceanografia). Universidade Federal de Pernambuco. 2007. 